\title{
Evaluation of Millennium Development Goals Process: Case of Albania
}

\author{
Elena Pici \\ Economics Department, Epoka University, Tirana/Albania \\ epici10@epoka.edu.al \\ Jonada Pasmaciu \\ Economics Department, Epoka University, Tirana/Albania \\ jpasmaciu10@epoka.edu.al

\section{Dr. Eglantina Hysa} \\ Lecturer at Economics Department, Epoka University, Tirana/Albania \\ ehysa@epoka.edu.al \\ Jona Hoxhaj \\ Economics Department, Epoka University, Tirana/Albania \\ jhoxhaj10@epoka.edu.al \\ Mergleda Hodo \\ Research Assistant at Economics Department, Epoka University, Tirana/Albania \\ mhodo@epoka.edu.al
}

\section{Doi:10.5901/mjss.2014.v5n14p33}

\section{Abstract}

Albania is one of 191 nations that in September 2000 adopted the Millennium Declaration and agreed to fight for Millennium Goals' achievement by 2015. Since then, Albania has delivered five National Reports (2002, 2004, 2005, 2009, 2010) on the progress made toward achieving MDGs and one Report (2007) is prepared by UNDP. In 2004, the Parliament of Albania passed a resolution in which not only supported the achievement of the $8 \mathrm{MDGs}$, but also included a 9th special goal: To establish and strengthen good governance. All the set of MDGs for Albania as defined by 2004, fully comply with the European Union integration's agenda. The areas covered by MDGs, complement with the implementations required by both Lisbon Strategy and Stabilization Association Agreement. This study analysis the progress done in the achievement of each goal for the Albania case.

Keywords: Millennium Development Goals, Albania

"Eradicating extreme poverty continues to be one of the main challenges of our time, and is a major concern of the international community. Ending this scourge will require the combined efforts of all, governments, civil society organizations and the private sector, in the context of a stronger and more effective global partnership for development. The Millennium Development Goals set time bound targets, by which progress in reducing income poverty, hunger, disease, lack of adequate shelter and exclusion - while promoting gender equality, health, education and environmental sustainability - can be measured. They also embody basic human rights - the rights of each person on the planet to health, education, shelter and security. The Goals are ambitious but feasible and, together with the comprehensive United Nations development agenda, set the course for the world's efforts to alleviate extreme poverty by 2015." United Nations Secretary-General BAN Ki-moon

\section{Introduction}

In 2000, 189 countries participated in the United Nations Millennium Summit and decided on the 8 Millennium Development Goals to be reached in 2015. After this first Summit, called Millennium Declaration, the second Summit 
related to the MDG was the World Summit in 2005. The aim of these goals was the convergence of developing countries with the developed ones, making further efforts in helping the poor countries to enhance their standard of living by undertaking reforms in the systems of these countries and to promote efficiency. The Millennium Development Goals are as follows:

1. Eradicate extreme poverty and hunger

2. Achieve universal primary education

3. Promote gender equality and empower women

4. Reduce child mortality

5. Improve maternal health

6. Combat HIVIAIDS, malaria, and other diseases

7. Ensure environmental sustainability

8. Develop a global partnership for development

9. * To establish and strengthen good governance (new goal added in 2004)

In order to fulfill these goals, 18 specific targets and the corresponding indicators were set. The calculation of these targets is crucial given that they are measurable and by putting everything in numbers the governments or the respective organization can easily identify the immediate needs and the weak/strong points in the way of prosperity. All these targets intend to further development and poverty eradication. The detailed information related to goals, targets and indicators is given in Appendix A.

The National Reports highlight the continuous commitment of Albanian government to achieve the goals. The goals have been an integral part of the National Strategies for Economic and Social Development as well as they have incorporated in certain laws. Mrs. Gülden Türköz Cosslett (2010), representative of UNDP in Albania has stated that Albania was the first country to set sub-objectives and the national goals for the planning of regional development.

However, despite the high political commitment, this does not ensure action. Mainly due to the economic crises, there is a slight decrease in Human Development Index, which despites ranking Albania as a country with High Human Development (UNDP, 2013), the index decreased from 0.801 in 2008 to 0.749 in 2013. Compared to other Balkan countries, Albania is doing better than Macedonia and Bosnia \& Herzegovina only. Among the main constrains of implementation are the lack of awareness and policy planning at the local level. That is why the goal's progress in not stable and it varies from one goal to the other.

\section{The Progress of Albania toward the MDG Achievement}

\subsection{Eradicate extreme hunger and poverty}

Eradicating extreme hunger and poverty has been a strategic priority of any government in Albania. The policies toward achieving this goal has been integrated in National Strategy for Development and Integration 2007-2013, the Strategy for Social inclusion 2007-2013, the Strategy of Social Protection 2007-2013 and the Strategy on Employment and Vocational Training 2007-2013 ( National report, 2010).

Based on the Strategy for Social inclusion 2007-2013, till 2015 the absolute poverty should be reduced with 12.2\% and there should be no family living in extreme poverty. Among the objectives to achieve this goal, the strategy has included: the formalization of the labor market, women participation in the labor market, education and professional training, providing social assistance etc.

Prior to 2008, Albania had a positive economic performance which was accompanied with an increase in employment and decrease in the poverty rate. From 2002 to 2008, there was a decrease in the poverty headcount from $25.4 \%$ to $12.4 \%$ (National Report, 2010). That is why, based on the LSMS data, UNDP Report in 2007 for Albania showed positive remarks about Albania's development and stated confidence that Albania would reach the goals by 2015.

However, after 2008, the low growth rate has caused again an increase in the poverty rate from $12.4 \%$ in 2008 to $14.3 \%$ in 2012 both in urban and rural areas. So, the challenge of the new government is to decrease back the poverty rate at least at the level of 2008. This surely requires a balanced economic growth and focus on social inclusion. There are some improvements in the social safety net for poor, providing them monthly economic support as well. Obviously, business formation is one of the main sources to increase employment rate, that is why attracting FDI remains a priority. Since the highest rate of poverty is present in rural areas, there have been set certain agencies to provide support in the form of small grants for investments. In overall, the current situation indicates that Albania stands at medium level chance to reach this goal by 2015 . 


\subsection{Achieve Universal Primary Education}

In order to achieve this goal, the government has prepared a National Strategy for Pre-University Education 2008 -2013. The strategy also reformatted the system, making the primary obligatory education 9 years instead of 8 years and also including a preparation year before enrolling in the elementary school. The financing of education has continuously had a special attention. Based on budget expectation of the Strategy (pg. 35-37), the total expenses of the Ministry of Education will increase from 32.634 ( million ALL in 2007 ) to 60.902 (million ALL in 2013). That is why, the probability of achieving the target of : Increase spending for basic education to the level of new EU member states, is high. In fact, some of the main achievements in education has been thanks to the developments in infrastructure.

The net primary school enrolment rates as reported by UNICEF Institute of Statistics and from national household survey reports of attendance at primary school, shows that $80 \%$ of Albanians attend a primary education.

In 2008, the average years of education period in Albania were 8.6, not only far below from the European standard of 17.4, but also lower compared to other Balkan countries. However, Albania is making progress since the average school enrollment years increased to 11.2 in 2010. The enrollment rate is bit higher for females (52.7\%) than for males (49.2). According to UNICEF Basic Indicators for Albania, the literacy rate in 2011 was $96 \%$. Anyhow, based on the last National Report (2010), there are little expectation that Albania will reach the target of: Ensure universal enrolment of basic education (1-9 years) by 2015

As in the other sectors, there are laws and strategies, but they lack the capacities and the resources needed for implementation. Government's long-term goal should be to develop a sustainable education system, which does not go through new experiments every time the minister changes position.

\subsection{Promote gender equality and empower women}

In 2010, the WHO summit took place in Durres. While evaluating the results made by countries toward MDGs achievement, it was realized a strong dependency between MDG3, MDG4 and MDG5. Empowering women through education is one of the key determinants of maternal and child health. Furthermore, accessing economic resources enables women to have more access to information and thus to make more rational choices regarding their health and the health of their children. Other issues such as gender-based violence, marriage at an earlier age should be challenged both by the health sector and by the institution which promote gender equality. Following this reasoning, Albania is trying to incorporate all the three goals in the same strategy.

On July 24th, 2008, Albanian Parliament, with the support given by OSCE, approved the law nr. 9970 'On gender equality'. Since it fist article the law states the protection and the equal treatment of women and men, their equal opportunities and chances to exercise their right, as well as their participation and contribution in the development of all social fields. By the article 11 of the law nr. 9970, it is founded also a National Council on Gender Equality with an advisory role. In the Ministry of Social Wealth fare, it is also a special directory dealing with gender equality and the family.

On 2007, the Council of Ministers has also approved a National Strategy and an Action Plan for achieving the Gender Equality. This strategy was re-adopted in 2010, with the perspective to be implemented till 2015. The four main objectives of this Strategy are:

- Fostering the legal and institutional mechanism

- Eliminating the stereotypes and the cultural practices which are harmful toward women

- $\quad$ Empowering economically the women

- Eliminating domestic and gender-based violence

Albania has made progress regarding the law mechanism to achieve this goal. Despite the law ' On gender Equality' on 2010 was approved also the law " On protection against discrimination'. Furthermore, the electoral code approved in 2011, setting the representative quotas for girls and women, has increased their participation in politics and decision making. This makes possible the achievement of the second target: Eliminate gender disparities in elected bodies, in decision making in central and local government, and in judicial system .

Regarding economic empowerment, women are still disadvantaged. Only $52 \%$ of women, compared to $73 \%$ of men are part of the labor force (INSTAT, 2013). However, according to the last National Report 2010, the greatest progress has been with respect to the 4th target, dealing with employment challenges. There are implemented certain projects to enhance women employment, there are lent small loans to develop women's businesses and there are implemented some social businesses with women as labor force focus. On the other part, there is a specific part of the budget given in the form of cash transaction to the families with a lot of children or with only the mother as a parent. A 
concern remains the women of the third age, unemployed since the 1990, who don't receive any concrete support and for the whom it is very difficult to prepare training programs.

Lastly, the gender equality is educated through being part of school's curricula as a specific subject and there is also a continuously sensibility campaign done from the media.

\subsection{Reduce child mortality}

According to UNICEF Basic Indicator (2011), infant mortality rate (under 1) is 14\% in Albania, while the neonatal mortality rate is $7 \%$. So, Albania has already achieved the target of neonatal mortality rate $11 / 100,000$ by 2015 , while there not so many chances to reach the infant mortality target: 10/1,000. However, Save the Children Report (2012), still ranks Albania as one of the countries with high mortality rate. Also, despite the decreasing rates, Albania still remains behind in achieving the goal compared to other Balkan countries. $18 \%$ of the mortal infants die since coming to live, while $50 \%$ of them die within the first month of life. This shows that achieving this goals is strongly linked with mother's health as well, thus achieving MDG 5.

In fact the challenge is not only to reduce the child mortality, but also to reduce the discrepancies of this mortality between urban and rural areas. Rural areas experience double the mortality rate of urban areas. There are also differences related to the mother's education level. The child of a mother with elementary education or less, is more risky to die within his/her first year of life compared to the child of the mother with secondary or higher education. Also, based on UNDP Report (2007), children under 5 years from low income families are $40 \%$ more in risk to die compared with children from middle of high income families. This result indicates that despite illness or complications during the birth, one of the main factors causing child mortality is malnutrition.

To conclude, more measures should be taken to ensure that vulnerable women get the appropriate support. Despite the law provides it, implementation measures should ensure free reproduction, maternal and child health services at any point of access. Also reforms with focus the quality of the health service should take place. This requires more budget to be allocated for the reform. In 2010, only 3\% of GDP was allocated to reduce child mortality and this percentage is far too low from the standard that EU countries are applying.

\subsection{Improve maternal health}

Ex- minister of Health, Mr. Vasili (2010) stated that Albania has improved several elements that ranks it among the countries which has done a lot of the improvements regarding maternal health. Albania has coverage of $98 \%$ of the population vaccinated.

In 2012, the Ministry of Health in collaboration with UNFPA launched the National Strategy of Contraceptive Covering for the period 2012-2016. The aim of this Strategy is to have an impact on family planning and to reach by 2016 $30 \%$ of the population using modern methods of contraceptives.

Based on the National Report (2010) 97\% of Albanian pregnant women receive antenatal care from a professional provider at least once during the pregnancy period. In urban areas, especially the cities located in the Center and West of Albania, this percentage is 100\%. Also the percentage of births attended by a professional assistant is high, $99.3 \%$ and only $3 \%$ out of them are home-deliveries. These achievements contribute also to the decrease of child mortality.

However, among main challenges are still the improvement of health service and free access to it. For example Roma community is one of the most marginalized group. Also women living in distant rural and mountain areas are too far from accessing free maternal health. The infrastructure of the hospitals is a concern as well. They lack spaces to hold the mothers same days after giving birth and they also lack diagnostic apparatuses or medicines. The reformation of the whole health system and not only of the maternal health care should be a focus of the current government.

\subsection{Combat HIV/AIDS and tuberculosis}

The first HIV case diagnosed in Albania was in 1993. Since then, the official number of persons with HIV virus reached 555 in 2012 ( 70\% of the which males and 30\% females) and only during 201270 new cases were diagnosed (Agolli, 2013). Generally, Albania fight toward HIVIAIDS is focused on its prevention through educative and informative channels.

Although the numbers are not alarming, the trend is increasing. That is why; the Ministry of Health in collaboration with the Institution of Public Health prepared a law on HIVIAIDS which was approved in Parliament in June 2008. The law has a specific importance because it states also the rights of these people and fights toward their discrimination. However, despite the law, it is necessary to approve a secondary legislation that focuses on its implementation, making 
sure that all their rights are respected.

Despite the above mentioned law, there is also law nr. 7761, dt. 19.10.1993 'On the prevention and combating of contagious diseases'. This law specifies that denunciation and protection against these diseases is compulsory. It also created a special institution dealing with such cases: The National Council of Immunization. Considering that Albania is not a country which has experienced serious problems with HIVIAIDS or contagious diseases, this goal is not among the ones which specially attracts the focus of the government and decision making bodies.

\subsection{Ensure environmental sustainability}

The environmental issues are never as ease as they look because they encompass several relationships which have the individual, both as a citizen and as a consumer, in the center of attention.

Albania has been active in ratifying the Aarhus Convention and also nationally there several laws as well as institutions taking care for the environmental sustainability. Apart from the primary institution, Ministry of Environment, there are the National Agency of Environment, responsible for monitoring the environment in different areas; Inspectorate of Environment, which check the impact of industrial activities in the environment and also Institute of National Health responsible to check the air pollution. However, according to the EU Progress- Report 2012, Albania has had little progress in adopting the legislation of acquis communitaire with regard to environmental issues and even less with regard to climate changes issues. According to this report, Albania lacks investment because of the absence of a specific budget. Despite public investments, Albania lacks also public awareness and legislative initiative.

The target of accessing safe water has experienced improvements, increasing the percentage from $69 \%$ in 2002 to $82.1 \%$ in 2009 . However, it is unlike that Albania will reach the target of $98 \%$ by 2015 .Generally there is a medium chance that Albania will reach the goal as e hole. A main role in its achievement can be played by international organization and national/international NGOs. In fact, World Bank and other international organizations have sponsored several projects ( even with educative focus), which have been implemented in collaboration with national partners like : Institute for the Protection of Environment or Cooperation \& Development Institute.

\subsection{Develop a global partnership for development}

During the years after the communism fall, Albania has managed sustainable developing partnerships. Even with respect to the MDG 8 achievement, Albania has made considerable progress, having thus all the chances to reach this goal. One of the main achievements has been the accomplishment of the third target: Improve access to ICT to the level of EU new member countries. Albania is in the phase of being transformed to an information society. Technological progress and the increase in the accessing rate of the information from the population, mainly through telecommunication devices or internet, will enable more informed and participating citizens.

According to the last National Report (2010), Albania has medium chances to reach the first target: Ensure partnership with donor community in order to increase aid effectiveness. Generally, the foreign aid is decreasing, due to the global economic crisis and to the fact that Albania is developing and is being considered more and more a country not in need in a lot of areas.

Nowadays, the focus of the global partnership is the attraction of FDIs. That is why, FDIs establishment in Albania is an integral part of the National Strategy for Businesses and Investments Development and also it is establish an Albanian Agency for the Development of Investments.

\subsection{Improve governance for all citizens}

The goal of achieving the good governance is very important for Albania, especially since April 2009 when it was submitted the application for European Union candidacy. This goal is multi-dimensional because it includes: the fight toward corruption, transparency from the government, free access to public services, citizen's participation in decision making etc.

The performance in achieving this goal's targets is mixed. The transparency dimension had one of its successes with the implementation of e-governance. There are also improvements and a specific focus on anti-corruption, property rights, the reform in the public administration etc. Anyhow, Albania is still far from reaching the first target: Governance in Albania approaches EU governance standards by 2015. This was also the 'confirmation' we got from European Commission, which on December 17th, 2013 postponed Albania's status approval. Except of the political stability indicator which has showed some improvements, the four others remain unchanged. The Corruption Perception Index 
(2013) still remains high 31, ranking Albania the 116th out of 177 countries. The other challenge is the rule of law. In order to reach this goal, Albania has to do several improvements especially with regard to politicians' accountability and citizens' participation in decision making.

\section{Conclusions and Recommendations}

In conclusion, Albania has done progress toward all goals' achievements. However the goal's progress differs from one goal to the other. Several laws and strategies with respect to each goal have been approved, but there are certain factors that impede their full implementation. One of the main factors is the global economic crisis, which has caused a decrease in the budget allocated for the achievement of these goals. This situation obviously has decreased the chances to achieve the goals compared to the period 2008 and before when the chances were generally very optimistic.

Albania has done progress in eradicating extreme poverty through the formalization of the labor market, through proving social assistance and through encouraging women participation in the labor market. This last tool has also helped in achieving gender balance. Improvements have been done also in the area of schools' infrastructure, but still the system as a hole needs to be consolidated. The common strategy in combating child mortality, HIVIAIDS and providing maternal health care has shown improvements as well, but a lot is still to be done with respect to the quality of the service and its free accessing. A little is done with regard to environmental sustainability, because Albania lacks both the legislative framework in this field and the public awareness. Still a lot is also to be done for the development of the global partnership (despite the achievement in the improving access to ICT) and improvement of the good governance. Albania should face challenges related with the corruption, transparency, reform of the public administration, property rights, citizen's participation in decision making etc. Not facing them with commitment and determination makes Albania far from approaching to EU governance standards by 2015.

Among main recommendations are:

- $\quad$ Ensuring balanced macro-economic growth

- Focus on social inclusion

- Empower women economically. Enhancing their labor opportunities through proving professional training, grants to start-up small businesses or implement social entrepreneurships

- Improving the quality of health services and ensuring its free access.

- Focusing on business development and FDIs attraction.

- Increasing politician's accountability and citizen's participation in decision making

\section{References}

Agolli, I. (2013). Human Rights of HIVIAIDS people in Albania. Retrieved January 2014

Albania National Institute of Statistics. (2013). Retrieved from http://www.instat.gov.al/al/home.aspx

Cosslett, G. T. (2010, July). Albania: Progress in achieving MDG. (ATSH, Interviewer)

Government of Albania, U. N. (2010). Albania National Report on the progress toward achieving the MDGs. Tirane.

Ministry of Education. (2007). National strategy for Pre- University Education. Retrieved January 2014

Ministry of Social Wellfare. (2007). National Strategy for Gender Equality. Retrieved 2014

Ministry of Social Wellfare. (2007). Strategy of Social Inclusion. Retrieved January 2014

Save the Children. (2012). Results for Children. Retrieved January 2014, from http://www.savethechildren. org/site/c.8rKLIXMGIpl4E/b.8663861/k.691F/Online_Library_Archives.htm\#Annual_Report_Archive

Transparent International (2013). Corrusption Perceptation Index. Retrieved January 2014, from http://www.transparency. org/cpi2013/results

UNDP. (2007). Millenium Development Goals. Retrieved January 2014

UNDP. (2013). Human Development Index. Retrieved January 2014

UNICEF INSTITUTE of STATISTICS (2011). Retrieved January 2014

Vasili, P. (2010, 09 28). Important steps in improving mothers and children's health. (B. Sot, Interviewer)

World Bank (2013). Living Standards Measurement Study. Retrieved January 2014, from http://econ.worldbank.org/wbsite/e xternal/extdec/extresearch/extlsms/0,,contentmdk:21610833 pagepk:64168427 pipk:64168435 thesitepk:3358997,00.html

World Health Organisation. (2010). Retrieved 2014, from Progress regarding MDG 3, 4 and 5: http://www.euro.who.int/en/healthtopics/health-determinants/millenium-development-goals/news/news/2010/10/progress-regarding-mdgs-3,-4-and-5.-draftconclusions-from-who-meeting-of-national-focal-points-for-family-and-community-health-in-durres,-albania. 
Appendix A: Official list of MDG indicators

\section{Goals and Targets (from the Millennium Declaration)} Goal 1: Eradicate extreme poverty and hunger

Target 1.A: Halve, between 1990 and 2015, the proportion of people whose income is less than one dolla a day

Target 1.B: Achieve full and productive employment and decent work for all, including women and young people

Target 1.C: Halve, between 1990 and 2015, the proportion of people who suffer from hunger

\section{Indicators for monitoring progress}

1.1 Proportion of population below \$1 (PPP) per day

1.2 Poverty gap ratio

1.3 Share of poorest quintile in national consumption

1.4 Growth rate of GDP per person employed

1.5 Employment-to-population ratio

1.6 Proportion of employed people living below $\$ 1$ (PPP) per day

1.7 Proportion of own-account and contributing family workers in total employment

1.8 Prevalence of underweight children under-five years of age

1.9 Proportion of population below minimum level of dietary energy consumption

\section{Goal 2: Achieve universal primary education}

Target 2.A: Ensure that, by 2015, children everywhere, boys and girls alike, will be able to complete a full course of primary schooling

2.1 Net enrolment ratio in primary education

2.2 Proportion of pupils starting grade 1 who reach last grade of primary

2.3 Literacy rate of 15-24 year-olds, women and men

\section{Goal 3: Promote gender equality and empower women}

Target 3.A: Eliminate gender disparity in primary and secondary education, preferably by 2005 , and in all levels of education no later than 2015

\section{Goal 4: Reduce child mortality}

Target 4.A: Reduce by two-thirds, between 1990 and 2015 , the under-five mortality rate

\section{Goal 5: Improve maternal health}

Target 5.A: Reduce by three quarters, between 1990 and 2015, the maternal mortality ratio

Target 5.B: Achieve, by 2015, universal access to reproductive health

\section{Goal 6: Combat HIVIAIDS, malaria and other diseases}

Target 6.A: Have halted by 2015 and begun to reverse the spread of HIVIAIDS

Target 6.B: Achieve, by 2010, universal access to treatment for HIVIAIDS for all those who need it Target 6.C: Have halted by 2015 and begun to reverse the incidence of malaria and other major diseases

\section{Goal 7: Ensure environmental sustainability}

Target 7.A: Integrate the principles of sustainable development into country policies and programmes and reverse the loss of environmental resources

Target 7.B: Reduce biodiversity loss, achieving, by 2010 , a significant reduction in the rate of loss

3.1 Ratios of girls to boys in primary, secondary and tertiary education

3.2 Share of women in wage employment in the non-agricultural sector

3.3 Proportion of seats held by women in national parliament

4.1 Under-five mortality rate

4.2 Infant mortality rate

4.3 Proportion of 1 year-old children immunised against measles

5.1 Maternal mortality ratio

5.2 Proportion of births attended by skilled health personnel

5.3 Contraceptive prevalence rate

5.4 Adolescent birth rate

5.5 Antenatal care coverage (at least one visit and at least four visits)

5.6 Unmet need for family planning

6.1 HIV prevalence among population aged 15-24 years

6.2 Condom use at last high-risk sex

6.3 Proportion of population aged 15-24 years with comprehensive correct knowledge of HIVIAIDS

6.4 Ratio of school attendance of orphans to school attendance of nonorphans aged $10-14$ years

6.5 Proportion of population with advanced HIV infection with access to antiretroviral drugs

6.6 Incidence and death rates associated with malaria

6.7 Proportion of children under 5 sleeping under insecticide-treated bednets

6.8 Proportion of children under 5 with fever who are treated with appropriate anti-malarial drugs

6.9 Incidence, prevalence and death rates associated with tuberculosis

6.10 Proportion of tuberculosis cases detected and cured under directly observed treatment short course
7.1 Proportion of land area covered by forest

7.2 CO2 emissions, total, per capita and per \$1 GDP (PPP)

7.3 Consumption of ozone-depleting substances

7.4 Proportion of fish stocks within safe biological limits

7.5 Proportion of total water resources used

7.6 Proportion of terrestrial and marine areas protected

7.7 Proportion of species threatened with extinction 
Target 7.C: Halve, by 2015, the proportion of people without sustainable access to safe drinking water and basic sanitation

Target 7.D: By 2020, to have achieved a significant improvement in the lives of at least 100 million slum dwellers

\section{Goal 8: Develop a global partnership for development}

Target 8.A: Develop further an open, rule-based, predictable, non-discriminatory trading and financial system Includes a commitment to good governance, development and poverty reduction - both nationally and internationally

Target 8.B: Address the special needs of the least developed countries

Includes: tariff and quota free access for the least developed countries' exports; enhanced programme of debt relief for heavily indebted poor countries (HIPC) and cancellation of official bilateral debt; and more generous ODA for countries committed to poverty reduction

Target 8.C: Address the special needs of landlocked developing countries and small island developing States (through the Programme of Action for the Sustainable Development of Small Island Developing States and the outcome of the twenty-second special session of the General Assembly)

Target 8.D: Deal comprehensively with the debt problems of developing countries through national and international measures in order to make debt sustainable in the long term
7.8 Proportion of population using an improved drinking water source

7.9 Proportion of population using an improved sanitation facility

7.10 Proportion of urban population living in slums

Some of the indicators listed below are monitored separately for the least developed countries (LDCs), Africa, landlocked developing countries and small island developing States.

Official development assistance (ODA)

8.1 Net ODA, total and to the least developed countries, as percentage of OECD/DAC donors' gross national income

8.2 Proportion of total bilateral, sector-allocable ODA of OECD/DAC donors to basic social services (basic education, primary health care, nutrition, safe water and sanitation)

8.3 Proportion of bilateral official development assistance of OECD/DAC donors that is untied

8.4 ODA received in landlocked developing countries as a proportion of their gross national incomes

8.5 ODA received in small island developing States as a proportion of their gross national incomes

Market access

8.6 Proportion of total developed country imports (by value and excluding arms) from developing countries and least developed countries, admitted free of duty

8.7 Average tariffs imposed by developed countries on agricultural products and textiles and clothing from developing countries

8.8 Agricultural support estimate for OECD countries as a percentage of their gross domestic product

8.9 Proportion of ODA provided to help build trade capacity

Debt sustainability

8.10 Total number of countries that have reached their HIPC decision points and number that have reached their HIPC completion points (cumulative)

8.11 Debt relief committed under HIPC and MDRI Initiatives

8.12 Debt service as a percentage of exports of goods and services

Target 8.E: In cooperation with pharmaceutical companies, provide access to affordable essential drugs in developing countries

Target 8.F: In cooperation with the private sector, make available the benefits of new technologies, especially information and communications
8.13 Proportion of population with access to affordable essential drugs on a sustainable basis

8.14 Fixed telephone lines per 100 inhabitants

8.16 Internet users per 100 inhabitants
8.15 Mobile cellular subscriptions per 100 inhabitants 